\title{
The Role and Value of the Athletic Trainer in the Chiropractic Medicine Setting
}

Nicholas Spangler, DAT, LAT, ATC*

*Community Care Network, Schererville, IN

\section{Full Citation}

Spangler N. The Role and Value of the Athletic Trainer in the Chiropractic Medicine Setting. Clin Pract Athl Train. $2021 ; 4(1): 66$.

https://doi.org/10.31622/2021/0004.1.11.

Presented at the 4rd Annual Athletic Trainers in the Physician Practice Society Meeting and Conference, February 26-27, 2021.

\section{ABSTRACT}

In the United States, back pain is the most common cause of activity limitation in people younger than 45 years, the second most frequent reason for visits to the physician, the third most common cause of surgical procedure, and the most frequently reported subcategory of musculoskeletal impairment in the United States of people aged up to 65 years (51.7\%). ${ }^{1}$ Chiropractors are healthcare professionals who are trained in the evaluation and treatment of this patient population and utilize a variety of skills like spinal manipulation, soft tissue mobilization, modalities, and therapeutic exercise. Athletic trainers are healthcare professionals whose educational and clinical background in musculoskeletal evaluation make them specifically suited to work alongside chiropractors as both providers utilize many of the clinical skills listed above. As the employment of athletic trainers in the physician practice setting continues to grow, the setting of chiropractic medicine offers athletic trainers unique opportunities that are both similar and different from that of the traditional orthopedic physician practice. Comparable to the orthopedic physician setting, athletic trainers can provide indirect value in the chiropractic setting through rooming patients, taking vitals, and charting during evaluations. However, the chiropractic setting also offers athletic trainers the unique opportunity to perform therapeutic exercise and manual therapy in the physician practice setting. By doing so, the athletic trainer can provide direct value to this setting by performing billable services that would otherwise not be offered without either the training of another provider or at the expense of the chiropractor's time. Specifically, using data from our practice, we see that an athletic trainer alone performs approximately $30 \%$ of the services billed for by the provider. When projecting the value of these services over a calendar year, an athletic trainer alone can provide up to $\$ 40,000$ worth of services in a practice operating at near full patient load. As athletic training continues to grow in the physician practice, the profession should continue to be aware of the variety of settings in which athletic trainers can provide value and practice near the top of their scope of practice. This presentation will overview the direct and indirect value an athletic trainer can provide in the chiropractic setting.

\section{Correspondence}

Dr. Nicholas Spangler, 1345 US 30, Schererville IN 46375

Email: spanglern1020@gmail.com

Twitter: @spanglernAT

\section{REFERENCES}

1. Andersson GB. Epidemiological features of chronic low-back pain. Lancet.

1999;354(9178):581-585. https://doi.org/10.1016/S01406736(99)01312-4. 